\title{
Educação como ferramenta de cidadania e desenvolvimento sustentável: nosso papel como educadores
}

\author{
Educación como herramienta de ciudadanía y desarrollo sustentable: \\ nuestro papel como educadores
}

\author{
Education as a skill of citizenship and sustainable development: \\ our role as educators
}

A proposta deste artigo é a utilização da Carta da Terra como fonte inspiradora, abordando a educação como uma importante ferramenta de cidadania e sustentabilidade planetária. Conjugamos a Carta da Terra às práticas inspiradas por Peter Senge, importante autor no cenário empresarial global, para uma educação crítica e transformadora em prol do despertar da reflexão de nossos educandos, em prol da Justiça Social e de mundo mais sustentável, propondo reflexões aos educadores, para nossos alunos.
The purpose of this article is to use the Earth Charter as an inspirational source, addressing education as an important tool for global citizenship and sustainability. We combine the Earth Charter with practices inspired by Peter Senge, lead author on the global business scenario, for a critical and transformative education, in order to help the reflection of our students reflect and act towards social justice and a more sustainable world, offering reflections to educators, for our students.
El propósito de este artículo es utilizar la Carta de la Tierra como fuente de inspiración, dirigiéndose a la educación como una herramienta importante para la ciudadanía global y la sostenibilidad. Combinamos las prácticas de la Carta de la Tierra e inspirados por Peter Senge, autor importante en el escenario global de negocios, para una educación crítica y transformadora para el despertar de la reflexión de nuestros estudiantes hacia la Justicia Social y un mundo más sostenible, ofreciendo reflexiones a los educadores, para los estudiantes.
Palavras-chave: Educação, Cidadania, Desenvolvimento Sustentável.

\section{Autora:}

\section{Maria Cecilia Trannin}

Post-Doctoral Fellow - Pesquisadora at CCIAM - Climate Change Research Group - Universidade de Lisboa (FCUL). Possui graduação em Comunicação pela UFRJ. PhD em Ecologia Social pela Universidade Federal do Rio de Janeiro - Instituto EICOS- Cátedra da UNESCO (2011). Coordenação do Curso Gestão Ambiental (graduação); MBA Biodiversidade e Sustentabilidade (EaD) e do MBA em Gestão Ambiental na UNESA - Centro I.

E-mail: maria.trannin@estacio.br

\section{introdução}

Notícias vindas de vários lugares do mundo, sob inúmeras formas midiáticas (TV, internet, telefones celulares, outdoors, Ipods e tantos outros meios de comunicação) chegam com uma velocidade muito maior do que podemos absorver e se afetados por elas. A informação que entra através dos nossos sentidos é impressionante: cerca de 400 bilhões de bits por segundo. É fato que nós não temos a capacidade de processar toda essa informação ao mesmo tempo. Ao mesmo tempo, a questão da problemática ambiental, das consequências de nossos processos produtivos, do consumo e descarte exacerbado e dos impactos causados pelo nosso modo de viver permeia toda discussão, debate e informação midiática da atualidade.

A natureza nos sinaliza sua fragilidade e a finitude de seus recursos, face aos nossos hábitos de consumo insustentáveis. diariamente toneladas e toneladas de resíduos são descartados, enquanto poluímos nossas águas e nossas terras, desmatamos desenfreadamente, levamos inúmeras espécies à extinção, reduzimos ecossistemas e descartamos uma imensa quantidade de resíduos diários. No Estado do Rio de Janeiro, por exemplo, apenas 3\% dos resíduos são reciclados. o desmatamento total da Amazônia, embora com um viés de queda, já causou a destruição de aproximadamente $17 \%$ da floresta, somente em sua parte brasileira. o cerrado brasileiro, que ocupa $24 \%$ do território nacional e é o segundo bioma com maior biodiversidade do Brasil já perdeu quase a metade de sua cobertura florestal original, numa extensão de quase um milhão de Km2. A área é superior ao estado no mato grosso e corresponde a 22 estados do rio de janeiro. quatro décadas é o tempo que resta de vida para a Mata Atlântica - a floresta que, em 1500, recobria todo o litoral brasileiro. Nessa velocidade, a floresta tem data para acabar: 2050. Estamos vivendo um modelo de vida que extrapola demasiadamente a capacidade de carga da terra.

Desta forma, de nada adiantará estudar, progredir e encontrar um espaço de trabalho na sociedade se não tivermos a nossa "casa", a Terra. Nosso desafio, como educadores é, ensinar a pensar, e, ao mesmo tempo, desenvolver uma consciência crítica capaz de mudar hábitos e atitudes, transformando realidades e sociedades em prol da sustentabilidade planetária. para alcançar tal aliança e construir essas oportunidades, é importante refletirmos sobre nosso papel enquanto educadores.

este artigo tem a proposta de inserir uma abordagem holística e sistêmica nos processos educativos. para tal, baseia-se em dois instrumentos: as ferramentas apresentadas por Peter Senge, autor do best-seller "A quinta disciplina", laureado pela 
Harvard Business Review como um dos cinco "melhores livros de negócios" das duas últimas décadas, e na carta da terra. peter Senge desenvolveu um método denominado "As cinco disciplinas".

para o autor, uma disciplina é "um treinamento consciente para incorporação de novos hábitos, como se fosse uma espécie de técnica, algo que treinamos e incorporamos em nossas decisões e ações." podemos, através do treinamento e olhar crítico, mudar nossas posturas e adquirirmos maior domínio sobre nossas ações, mas dominar uma disciplina não é possuí-la. É um processo, é um comprometimento para a vida.

São cinco as disciplinas propostas por Senge: a maestria pessoal, a ruptura de modelos mentais, a visão compartilhada, o Aprendizado coletivo e o pensamento Sistêmico. com elas podemos aprender a pensar paradoxalmente, ver oportunidades antes não percebidas, termos maior clareza de pensamento e ideias mais criativas.

Além disso, como inspiração base, o artigo baseia-se nos seguintes princípios da carta da terra:

- Integrar, na educação formal e na aprendizagem ao longo da vida, os conhecimentos, valores e habilidades necessárias para um modo de vida sustentável;

- prover a todos, especialmente a crianças e jovens, oportunidades educativas que lhes permitam contribuir ativamente para o desenvolvimento sustentável;

- reconhecer a importância da educação moral e espiritual para uma condição de vida sustentável.

$\mathrm{O}$ artigo oferece assim estratégias pedagógicas que podem integrar na Educação Superior algumas reflexões necessárias, abordando a necessidade do desenvolvimento do pensamento sistêmico, do aprendizado colaborativo e contínuo, a inserção da temática e problemática ambiental de forma transdisciplinar, o desenvolvimento de habilidades cognitivas e relacionais, e a compreensão da valorização da cidadania como dimensão da própria educação.

\section{Desenvolvimento}

embora a realidade a nossa volta mude o tempo todo, desconstruindo saberes e comprovando novos fatos, criando cenários onde até o estudo da replicabilidade da vida humana é possível temos ainda um grande paradoxo: nossa realidade interna, nossos hábitos arraigados em tantos anos de consumo e descarte. É difícil mudar essa realidade, pois não paramos para "percebê-la". Nos acostumamos a "não ver", criamos "padrões mentais", modelos ou enquadramentos, como as molduras nas quais colocamos quadros e pinturas. congelamos nossas percepções e dificultamos a chegada de novos hábitos e atitudes. Adotamos com facilidade uma nova mídia interativa e nos conectamos sem fios com o outro lado do mundo, mas continuamos não compreendendo, de fato, a finitude de nossos recursos naturais e a complexidade dos processos produtivos. Acreditamos que basta "fechar a torneira para economizar água", mas comemos carne todos os dias, ignorando o gasto de água embutido na criação, processamento e abate dos animais (isso sem falar dos processos extremamente vis e cruéis aos quais os submetemos para nosso consumo).

Segundo peter Senge, para mudar uma organização é preciso primeiro empreender uma transformação individual. Nossos estudantes, e aqui falamos dos estudantes universitários, justamente aqueles que estão mais próximos do processo coletivo de decisão e transformação de realidades, vivem neste tempo mutável e midiático, a única certeza é a mudança cons- tante. Quando falamos em ensinar, falamos da necessidade de adaptação e compreensão deste mundo. falamos de despertar para uma consciência efetivamente crítica e transformadora, que de fato compreenda a complexidade e a inter-relação entre nossas escolhas e seus impactos, sobre a nossa responsabilidade na construção de uma sociedade mais justa e menos desigual, sobre o nosso desafio de transformar hábitos e atitudes, de "predadores e caçadores" em "construtores" de um mundo mais justo e solidário. Assim, utilizamos as ferramentas propostas por Peter Senger como fonte de inspiração, para refletirmos juntos, transportando esse conceito para o processo educativo, o professor deve assumir uma nova forma de atuação.

\section{Maestria Pessoal}

maestria pessoal é, por assim dizer, a arte do crescimento pessoal e do aprendizado. pessoas com essa disciplina incorporada em suas ações buscam continuamente expandir a capacidade de criar os resultados que realmente desejam. ela vai além das competências e habilidades, embora requeira competência e habilidades. tem a ver com ser criativo, em vez de reativo.

esta é a disciplina da aspiração, do sonho, da motivação. envolve o pensar sobre o que se quer atingir e alcançar como indivíduo. para dominá-la, devemos balancear o que vivemos no momento com o que queremos ser, criando uma visão pessoal. A justaposição da visão (o que queremos) e uma visão clara de onde estamos pode gerar tensão. essa é uma tensão positiva, criativa, vital para nossa evolução e transformação. Se visualizarmos uma banda elástica, que puxamos para um lado e para o outro compreenderemos a tensão entre realidade e visão. Aprender a lidar com essa disciplina expande a nossa capacidade de fazer escolhas e de atingir outros, novos resultados. o primeiro passo para dominar essa disciplina é ensinar aos alunos a identificar o que é importante para nós e para eles. Será que realmente precisamos tudo que consumimos? Já paramos para pensar no desgaste que a terra está sofrendo? como educadores, procuramos inserir a temática através de exemplos aplicados às "nossas" disciplinas? Incentivamos novas práticas reflexivas? Conversarmos com os alunos para que exerçam sua cidadania, desenvolvam sua visão pessoal de mundo, da realidade que possuem hoje e da realidade que querem criar para si e para seus futuros filhos? É fundamental enxergar "o todo" e a complexidade em cadeia das relações. É importante mostrar aos alunos que ser honesto é não fingir que está tudo bem.

com esta disciplina, treinamos o nosso caminhar direcionado para os objetivos que queremos alcançar. mover em uma direção implica em saber onde você está agora. pessoas que dominam essa disciplina nunca "chegam ao ponto final", estão sempre buscando, ou seja, o aprendizado é constante. como educadores, devemos ensinar que dominar essa disciplina é lutar, constantemente, contra as forças que nos puxam para trás, acreditando que a realidade somos nós que fazemos, como professores, como lideres comunitários, como empresários, como técnicos de meio ambiente, como cidadãos deste mesmo mundo. É mover adiante, a despeito dos problemas, integrando verdade, comprometimento, sonho, persistência, razão e intuição. Tendo compaixão, aprendendo e ensinando, conjugando intuição e racionalidade.

uma antiga história de autor desconhecido nos conta que um homem cego estava vagando perdido em uma floresta e tropeçou em um homem que não podia andar. Iniciaram uma conversa sobre a fatalidade da vida. O homem cego disse: " $E u$ 
estou vagando pela floresta toda minha vida e não encontro a saída". o outro respondeu: "Eu estou caído na floresta por toda minha vida e não consigo andar". de repente, o homem que não podia andar exclamou: "Eu tenho uma solução! Você me carrega no colo e eu te mostro como o caminho". Não somos tudo, mas ao somarmos forças podemos ser tudo.

Como falou Carl Jung, psiquiatra suíço, fundador da Escola Analítica de psicologia, autor de inúmeros livros e introdutor do termo inconsciente coletivo, "Quem olha para fora, sonha. Quem olha para dentro, desperta." como educadores, devemos difundir aos alunos o conceito de maestria pessoal, em nossas aulas, estimulando-os a identificar onde estão agora e onde querem chegar, fazendo-os co-relacionar a situação pessoal de cada um e a mudança no contexto sócio-político-ambiental do seu entorno e da sociedade com um todo.

Sem mudanças internas, estaremos sempre comentando, com distanciamento, os últimos acontecimentos e fatos, as catástrofes da hora, os vulcões e terremotos do momento, sem abordar suas causas, sem efetivamente provocar mudanças nas atitudes dos estudantes, futuros empresários que deverão assumir seus papéis tanto como cidadão. queremos também sugerir que o cenário de nossas aulas apresente e aborde a temática socioambiental de forma interdisciplinar, através de exemplos inseridos nas nossas disciplinas, ao mesmo tempo em que, como educadores, ofereçamos conhecimentos para a aquisição de consciência crítica, tão necessária à transformação que queremos e precisamos ter para conservar a vida na Terra. A ideia é que, sejam quais forem as disciplinas das quais estivermos à frente, caminhemos com o propósito de abordar e desenvolver a questão da necessidade das disciplinas internas, ferramentas necessárias à absorção de novos hábitos e atitudes sustentáveis, bem como a exposição dos cenários socioambientais que temos e como os queremos transformar, no caminho para uma vida mais sustentável.

\section{Modelos Mentais}

A segunda disciplina que devemos abordar em nossas aulas chama-se Modelos Mentais. Conforme vamos aprendendo, cristalizamos informações em nossas redes neurais. Não temos, em nossas mentes, famílias, trabalho, comunidades. Temos imagens, histórias, representações mentais, generalizações. Essas informações geram modelos mentais. os modelos mentais são personagens ativos em nossas vidas, pois direcionam nossas ações. os modelos mentais interferem na nossa forma de perceber a realidade. Eles mudam nossa forma de observá-la. Entramos com amigos em uma festa. Cada um de nós irá notar algo diferente, a presença de pessoas distintas. percebemos a realidade de acordo com nossos sentidos e com nossos modelos. Se estivermos atentos e disciplinados, passamos a questionar se os nossos modelos são de fato importantes e condizentes com o que queremos. Albert einstein uma vez escreveu: "Nossas teorias determinam nossas medidas". para aprender e inovar, precisamos ensinar nossos educandos a visualizar seus modelos mentais e praticar sua ruptura.

A empresa americana Harley Davidson, fabricante de uma das marcas de motocicletas mais conhecidas do mundo, encarou o desafio de romper com modelos mentais de seus executivos. $\mathrm{Na}$ busca de novas invenções, criou o exercício "mentor circular", que consistia em escolher pessoas de variadas posições na empresa para compartilhar seu dia-a-dia. As pessoas deveriam, como critério de escolha, possuir boa capacidade de comunicação e habilidade de ouvir e influenciar os outros. Baseada na idéia "crie a demanda, produza e ofereça serviços", executivos, mecânicos, engenheiros de produção, entre outros, contavam para os colegas, em um círculo, as visões de suas tarefas, pensamentos e posições na empresa. $\mathrm{O}$ jogo funcionou.

o modelo estava baseado, basicamente, em dois pilares: reflexões e inquisições. Pensar sobre e perguntar. Quanto mais perguntas, melhor. ouvir. encorajar o outro a ver o seu lado da moeda. Enxergando outras perspectivas, iniciamos o processo de questionamento interno das nossas. Sair do pensamento linear (o que eu enxergo) e entrar no pensamento circular exige pratica. É a prática de advogar suas idéias e defendê-las, ao mesmo tempo em que nos deixamos livres para receber novas perspectivas. Romper modelos mentais é um desafio que vale a pena, pois nos abre a novas oportunidades de aprendizado. para inovar, é preciso estar aberto. como educadores, o incentivo a essa prática é parte da nossa Missão, de Educar para Transformar.

\section{Visão Compartilhada}

A terceira disciplina, visão compartilhada, envolve buscar agregados para o seu sonho, montar um time de apoio, criar um sentimento em comum. uma visão compartilhada não é uma idéia, como "liberdade". É muito mais uma força no coração das pessoas, uma força que inspira a buscar apoio nos outros para aumentá-la. Não é abstrata, é palpável. para compartilhar a visão é preciso primeiro senti-la, internamente. A visão compartilhada cria uma espécie de excitação, um borbulhar interno, um desejo de ação. ela move e comove, leva adiante sonhos e aspirações. ela emerge, primeiramente, de uma visão interna pessoal. Neste sentido, a maestria pessoal, primeira disciplina aqui apresentada, muito nos ajuda, pois nos incita ao comprometimento, à tensão criativa da mudança.

Sentir algo de forma intensa contagia. Não é preciso convencer ninguém. A palavra que bem descreve o sentimento desta disciplina é entusiasmo. vem de dentro. traduz-se em energia. É uma energia positiva. Exclui o "não". Uma proibição, por exemplo, "Proibido fumar" não gera uma visão compartilhada. um desejo de ajudar, de mudar uma realidade, de construir algo mais humano e solidário sim.

Como em uma catástrofe, quando as pessoas se unem em prol das outras ou de uma situação, precisamos, como educadores, oferecer motivações aos alunos para lutar por um mundo mais justo e equalitário. Assim, os educandos passam a compartilhar a mesma visão e os conecta. descobrem, nesta buscam uma energia antes não conhecida, que podem ser motivados a lutar por uma causa, seja compartilhando os conhecimentos aprendidos em sala de aula com as comunidades do entorno, seja abraçando a causa de conservação de uma determinada região, ou um mutirão de limpeza e reestruturação de um parque ou mesmo uma determinada área urbana. os alunos devem ser motivados a agir em conjunto, por uma causa. Isso também faz parte de nossa missão como educadores.

\section{Aprendizado coletivo}

esta disciplina trata da interação em grupo, com um ou mais objetivos em comum. Isso forma um coletivo. Atenção à palavra: Inter-ação: ação entre as partes. A disciplina denominada "Aprendizado coletivo" requer diálogo e muita conversa. diálogo, de origem grega dia-logos, significa deixar fluir a palavra, pensar junto. Atingir resultados no coletivo que não poderiam ser obtidos individualmente. Dialogo é diferente de discussão, envolve troca de opinião, ouvir o outro. coletivo não é grupo, tem liga, tem algo que os une. Pode ser definido com um conjunto de partes que defende os mesmos objetivos, cada um com a sua função, seu microcosmo que interfere no resultado. 
como em bando de pássaros que voa alinhado, cada um na sua posição, ela nos impele à comunhão de forças, a assumir nossa posição no bando. Aprender a usar e ensinar como usar essa disciplina envolve mobilizar energia para atingir objetivos comuns, verificando os talentos, habilidades e competências de cada um, de forma a alinhá-los em um aprendizado coletivo e a buscar a formação de seus próprios coletivos. Trabalhar com a postura de estimular os alunos a aprender e estudar coletivamente, ouvindo e respeitando o outro.

Nunca houve tanta necessidade de aprendizado e trabalho coletivo como agora, pois as ações que precisamos empreender para conservação da natureza e da vida humana no planeta não podem ser realizadas sem um esforço coletivo, sem aprendizado e ação conjunta. É preciso muito treinamento para o aprendizado desta disciplina. manter a visão pessoal, buscar uma visão no grupo que possa ser compartilhada e integrá-la no coletivo.

\section{Pensamento Sistêmico}

o pensamento Sistêmico é chamado de quinta disciplina. pensar sistemicamente é quebrar a linearidade dos encadeamentos. Não há fim, não há começo, pois um leva ao outro. Há círculos. Através desta disciplina devemos ensinar aos nossos educandos a perceber a interdependência das coisas, da natureza, das pessoas. É baseada na circularidade de nossas ações e nos resultados que geram. Às vezes, uma pequena ação pode desencadear uma grande mudança sistêmica. Sistemas vivos possuem sua própria integridade. Dividir um elefante em dois não produz dois elefantes, mas duas metades. desenvolver o pensamento sistêmico é trabalhar a habilidade de ver o todo. A beleza de uma flor, de uma pessoa ou um poema está no todo. Para exercer e ensinar como praticar essa disciplina, é preciso elevar o pensamento, deslocá-lo das noções de tempo e espaço. Algumas vezes apenas podemos sentir o efeito de nossas ações apenas muito tempo depois, ou até nem sentiremos esses efeitos nas nossas vidas, mas serão experimentadas pelas gerações por vir. grandes problemas, como o aquecimento global, a extinção das espécies, a conservação das águas, entre outros, exigem o pensamento sistêmico. Para pensar sistemicamente, temos que ver a estrutura que se esconde em situações complexas, reestruturar nossa maneira de pensar. talvez seja a disciplina mais difícil de ensinar e aprender, mas é nesta disciplina que as quatro disciplinas apresentadas acima apresentadas estão fincadas.

para melhor entender o pensamento sistêmico ou a quinta disciplina, já que esta é base e o fim de todas as outras, falaremos agora sobre complexidade sistêmica. Quando examinamos de perto as teorias sobre os processos que geram os organismos vivos, percebemos que eles encadeiam-se numa rede química, que é característica fundamental da vida. Assim como os ecossistemas são compreendidos em função da noção de teia alimentar, ou redes de organismos, assim também os organismos são concebidos como rede de células, órgãos e sistemas orgânicos; e as células, como rede de moléculas.

A ciência do século passado adotava a mecânica clássica como modelo do pensamento científico. Este pensamento entende as coisas como mecanismos e sistemas fechados. A ciência de nossos dias adota o organismo vivo como modelo, o que equivale a pensar em sistemas abertos, como redes. os sistemas são percebidos como orgânicos, interconectados, interdependentes e, portanto, complexos. A teoria da complexidade sistêmica rompe com três paradigmas científicos muito conhecidos: a simplicidade, a objetividade e a estabilidade.

o pressuposto da simplicidade ou a crença em que separando-se o mundo complexo em partes, encontram-se ele- mentos simples ou que é preciso separar as partes para entender o todo tira o objeto de estudo dos seus contextos, prejudicando a compreensão das relações entre o objeto e o todo. $\mathrm{O}$ contexto faz parte do todo e modifica as relações entre as partes. Podemos visualizar o poder do contexto se pensamos em uma sociedade, cidade ou país que acaba de passar por uma catástrofe. É possível considerar as pessoas, ou parte do sistema, sem considerar o que o(s) envolve no momento? o pressuposto da estabilidade trabalha com a crença de que o mundo é estável, previsível e controlável. O exemplo da catástrofe também pode ser aplicado aqui. por mais que tenhamos instrumentos avançados de detecção de falhas sísmicas e medição, temos como antecipar e evacuar uma cidade dias antes de um abalo sísmico?

o pressuposto da objetividade acredita que "é possível conhecer objetivamente o mundo tal como ele é na realidade" e exige a objetividade como critério de cientificidade. Se o observador, ou sujeito incorpora a sua realidade através de suas percepções, como podemos considerar o mundo pelas lentes puras da objetividade?

David Hume, irlandês que viveu mito tempo na França, pensador do século XvIII , autor da obra prima " o tratado da Natureza Humana" e uma cativante figura da história da filosofia, nos ilustra isso de forma comovente, com apenas algumas frases: "A beleza das coisas existe na mente de quem as contempla. À parte da matemática, não conhecemos nada com certeza. Mas ainda temos que viver e viver é agir. Todas as nossas ações têm que se basear em suposições sobre a realidade".

A idéia de complexidade sistêmica nos leva a crer que os três pressupostos acima mencionados não permitem que compreendamos o universo na sua plenitude, pois esquecemos de ver as relações, as interdependências, as sinergias decorrentes das múltiplas mudanças que ocorrem o tempo inteiro no mundo. Hoje sabemos que o mundo não está pronto e sim em constante processo de transformação e que fazemos parte desta constante (re)construção. Assim sendo, não pode ser controlado e previsível. Aprendemos também que a realidade não existe objetivamente, pois depende das lentes do olhar de quem a vê. como escreveu capra: "Minha decisão consciente sobre a forma como vou observar um elétron irá até certo ponto determinar-lhes as propriedades. Se eu fizer uma pergunta própria de partícula, ele me dará resposta de partícula. Se fizer uma pergunta própria de onda, ele me dará resposta de onda."

conclusões? respostas? Não temos, mas isso não impor ta. como disse mário quintana, no pequeno grande poema As indagações: "A resposta certa, não importa nada: o essencial é que as perguntas estejam certas." quebra de paradigmas, realidade, compreensão do mundo, tudo está em construção e essa é a sua verdadeira beleza! É fundamental que exerçamos nosso papel como educadores para de modo a lutar pelo desenvolvimento sustentável do país e formar egressos que busquem tanto a prática de cidadania, ação individual, quanto o exercício de responsabilidade Socioambiental (ação empresarial, a ser desenvolvida e ativada em seus postos de trabalho).

Assim, é importante que tenhamos como estratégia de ensino a inserção destas abordagens acima demonstradas, denominadas "cinco disciplinas", que podem ser transmitidas aos nossos alunos de forma gradual, exemplificada e prática, convidando-os a exercitar cada uma delas no seu dia-a-dia, dentro e fora do contexto universitário. Devemos motivar nossos alunos a formarem redes de trabalho, de fraternidade e cooperação mútua. A vida natural nos dá importantes aprendizados da importância do coletivo e do agir em conjunto. devemos tentar conhecer a realidade que 
queremos transformar, sabendo que somos ao mesmo tempo livres para escolher nosso caminho e interdependentes. como educadores, é importante que estimulemos nosso alunato a buscar as causas da problemática socioambiental, através de exemplos e casos diários, reservando alguns minutos finais de nossas aulas para essa discussão, estimulando-os a trazer notícias de jornal e revistas da atualidade a serem compartilhas com a turma, gerando novos conhecimentos e formas de pensar.

\section{Considerações finais}

Como vimos, tudo depende de nós da forma como iremos perceber a realidade e atuar sobre ela. precisamos mudar, internamente, para provocar as mudanças que queremos, precisamos e devemos efetuar no mundo. Compreender os padrões, pensar de forma complexa, romper com as linhas de produção de pensamento e ação pré-definidas. Eis a nossa tarefa, como educadores e educados, cidadãos do mesmo planeta.

Um novo perfil de atuação por parte dos homens desse tempo é essencial e diz respeito à sobrevivência de nossa vida no planeta. uma atuação sistêmica, que consiga vencer as barreiras e adversidades e encará-las como oportunidades. Conflitos, problemas, obstáculos sempre existirão. São importantes. Nos desafiam a crescer e transformar resistências em colaborações, nos fazem resilientes. É nesse contexto que se define uma nova forma de atuação do educador, baseada nos princípios da transformação individual e coletiva, na aquisição e transmissão de um novo conjunto de habilidades. Essas habilidades nos fazem perceber o mundo em sua complexidade, de uma forma nova e mais holística, gerando mudanças em nossas vidas e em nossas organizações.

Quando mudamos nossa forma de perceber, mudamos nossa forma de agir individualmente e no coletivo, passamos a ver o mundo de forma diferente. Contagiamos aos que estão a nossa volta. Criamos, dessa forma, uma nova realidade. Toda mudança é um desafio. Quando aqui dizemos mudar, queremos dizer ensinar e aprender.

capra sugere que as novas ciências podem colaborar com idéias, conhecimentos e imagens para uma nova compreensão do mundo contemporâneo. uma perspectiva que visualiza o universo como um sistema complexo, imprevisível, interativo, muito distante dos modelos reducionistas, estáveis e objetivos do século xvII. A decisão é nossa, pois a mudança deve ser iniciada dentro de nós. Assim, se conjugarmos a observação da problemática e das soluções socioambientais em sala de aula com o desenvolvimento das cinco disciplinas por nós apresentadas, em pequenos intervalos entre a difusão dos conhecimentos do conteúdo programático ao qual estamos vinculados, teremos avançado na construção da educação para a sustentabilidade.

o presente que vivemos é delicado, a natureza vem nos dando inúmeros sinais de sua fragilidade e, ao mesmo tempo, de sua potência destrutiva (ou reconstrutiva?). ela se reorganiza, da forma como sabe e como pode, em sua complexidade sistêmica, alterada por nossos impactos. Uma forma que podemos chamar de "quântica", ou integrada em sua complexidade. Uma percepção que vai além das aparências, que enxerga as partes que compõem o todo e o todo como um resultado das partes, e que, além disso, percebe as relações entre cada um dos elementos que integra o conjunto. falamos de despertar para uma consciência efetivamente crítica e transformadora, que de fato compreenda a complexidade e a inter-relação entre nossas escolhas e seus impactos, sobre a nossa responsabilidade na construção de uma sociedade mais justa e menos desigual, sobre o nosso desafio de transformar hábitos e atitudes, de "predadores e caçadores" em "construtores" de um mundo mais justo e solidário.

Como posto nos desafios da Carta da Terra, importante documento para o século xxI redigido coletivamente por pensadores e educadores na rio-92, a escolha é nossa, pois devemos "formar uma aliança global para cuidar da Terra e uns dos outros ou arriscar a nossa destruição e a da diversidade da vida.'

O tempo que temos é o tempo em devemos fazer acontecer. que o nosso tempo seja lembrado pelo despertar de uma nova reverência face à vida, pelo compromisso firme de alcançar a sustentabilidade, a intensificação dos esforços pela justiça e pela paz e a alegre celebração da vida. que nós, educadores, possamos ser os arautos deste processo.

\section{Referências}

ARANHA, José Alberto S. - Interfaces: A chave para compreender pessoas e suas relações em um ambiente de inovação - São paulo: editora Saraiva, 2009.

ARNTZ, William - Quem Somos Nós? A descoberta das infinitas possibilidades de alterar a realidade diária / William Arntz, Betsy Chase e Mark Vicente - Rio de Janeiro: Prestígio Editorial, 2007.

CAPRA, Fritjof - As Conexões Ocultas: Ciência para uma vida sustentável - São Paulo: Cultrix: 2005.

CARTA DA TERRA, disponível em http://www.cartadaterrabrasil. org/prt/text.html, acesso em 05/10/2014

INSTITUTO ETHOS - disponível em www.ethos.org, acesso em $05 / 10 / 2014$

levINAS, e. - Humanismo del outro hombre, Siglo XXI, México: 1993.

SeNge, peter - The Dance of Change: The Challenges to Sustaining Momentum in Learning Organizations / Art Kleiner, Charlotte Roberts, Richard Ross, George Roth, Bryan Smith - New York: Currency double day, 1999.

SeNge, peter - The Fitth Discipline: The Art \& Practise of the Learning Organization - New York: Currency Double Day, 2006.

Soto, eduardo - Comportamento Organizacional: o impacto das emoções - São paulo: pioneira thompson learning, 2002.

trANNIN. m.c - Sustentabilidade de comunidades \& meio ambiente Marketing \& Comunicação: construindo uma articulação in la Sustentabilidad Hoy. 2005- Fundación CEPA Argentina: 2005. 